\title{
Evolution of olivine lattice preferred orientation during simple shear in the mantle
}

\author{
Jessica M. Warren, Greg Hirth and Peter B. Kelemen
}

April 3, 2008

\section{Abstract}

Understanding the variation of olivine lattice preferred orientation (LPO) as a function of shear strain is important for models that relate seismic anisotropy to the kinematics of deformation. We present results on the evolution of olivine orientation as a function of shear strain in samples from a shear zone in the Josephine Peridotite (southwest Oregon). We find that the LPO in harzburgites re-orients from a pre-existing LPO outside the shear zone to a new LPO with the olivine [100] maximum aligned sub-parallel to the shear direction between $168 \%$ and $258 \%$ shear strain. The strain at which [100] aligns with the shear plane is slightly higher than that observed in experimental samples, which do not have an initial LPO. While our observations broadly agree with the experimental observations, our results suggest that a pre-existing LPO influences the strain necessary for LPO alignment with the shear direction. In addition, olivine re-alignment appears to be dominated by slip on both (010)[100] and (001)[100], due to the orientation of the pre-existing LPO. Fabric strengths, quantified using both the J- and M- indices, do not increase with increasing shear strain. Unlike experimental observations, our natural samples do not have a secondary LPO peak. The lack of a secondary peak suggests that subgrain rotation recrystallization dominates over grain boundary migration during fabric re-alignment. Harzburgites exhibit girdle patterns among [010] and [001] axes, while a dunite has point maxima. Combined with the observation that harzburgites 
are finer grained than dunites, we speculate that additional phases (i.e., pyroxenes) limit olivine grain growth and promote grain boundary sliding. Grain boundary sliding may relax the requirement for slip on the hardest olivine system, enhancing activation of the two easiest olivine slip systems, resulting in the [010] and [001] girdle patterns. Overall, our results provide an improved framework for calibration of LPO evolution models.

\section{Introduction}

Understanding olivine orientation as a function of shear strain is critical for quantifying relationships between the kinematics of deformation and the direction and magnitude of seismic anisotropy. For example, constraining the variation of olivine lattice preferred orientation (LPO) produced during simple shear is key to interpreting seismic anisotropy in terms of upper mantle convection (Hess, 1964; Nicolas and Christensen, 1987; Ribe, 1992; Mainprice and Silver, 1993; Blackman and Kendall, 2002; Wenk, 2002). The relationships among olivine deformation, LPO development and seismic anisotropy have been examined experimentally (Nicolas et al., 1973; Zhang and Karato, 1995; Bystricky et al., 2000). Observations from these experiments have been used to place constraints on models (e.g., Ribe and Yu, 1991; Wenk and Tomé, 1999; Tommasi et al., 2000; Kaminski and Ribe, 2001; Blackman et al., 2002; Conrad et al., 2007) that predict LPO development and thus upper mantle seismic anisotropy. Application of these models to deformation in the earth is improved by comparison of experimental results to rocks deformed under natural conditions, i.e., at lower stress and strain rate than can be achieved in laboratory experiments. To this end, we analyzed the evolution of olivine LPO as a function of shear strain in naturally deformed peridotites from a shear zone in the Josephine Peridotite in southwest Oregon.

Mantle anisotropy results from ductile flow in the asthenosphere by dislocation creep, which produces alignment of elastically anisotropic minerals. Olivine and orthopyroxene, the dominant mineral phases in the upper mantle, have orthorhombic symmetry and are anisotropic ( $\mathrm{Vp}$ 
anisotropies of $22 \%$ and 16\%, respectively; Nicolas and Christensen, 1987). At upper mantle pressure and temperature conditions, they deform by dislocation creep, resulting in an LPO. Deformation is principally accommodated by slip on (010)[100] and (001)[100] in olivine and on (100)[001] in orthopyroxene. At depths greater than $250 \mathrm{~km}$, anisotropy rapidly decreases and this has been interpreted as either a transition to diffusion creep (Karato, 1992) or to dislocation creep with a different slip system (Mainprice et al., 2005).

Zhang and Karato (1995) carried out simple shear experiments on olivine aggregates at $1200^{\circ} \mathrm{C}$ and $1300^{\circ} \mathrm{C}$ over a range of shear strains to investigate olivine fabric evolution. They found that the originally random fabric of their aggregates developed an LPO with a [100] maximum parallel to the flow direction by a shear strain of $\sim 150 \%$, as had previously been suggested experimentally by Nicolas et al. (1973). The Nicolas et al. (1973) experiments were performed in an axial geometry, but bubbles in olivine grains aligned with the flow direction at high strain and were interpreted to have deformed by simple shear. Bystricky et al. (2000) demonstrated that the [100] alignment persists to high shear strains $(\sim 500 \%)$.

The initial theoretical treatments of olivine LPO assumed that olivine grain orientations are controlled by finite strain (e.g., McKenzie, 1979). As (010)[100] has the lowest critical resolved shear stress (Durham and Goetze, 1977; Bai et al., 1991), the olivine [100] axis was predicted to align with the finite strain ellipsoid (McKenzie, 1979; Ribe, 1992). However, experimental results (Nicolas et al., 1973; Zhang and Karato, 1995; Bystricky et al., 2000) indicate that the olivine [100] maximum only coincides with the finite strain ellipsoid at strains $<100 \%$. This alignment may be more a coincidence than an indication of control on the fabric by the strain geometry. In viscoplastic self-consistent (VPSC) models (Wenk et al., 1991; Lebensohn and Tomé, 1993; Tommasi et al., 2000) the olivine [100] maximum approaches the flow direction at a rate intermediate between the finite strain model and experimental observations. In models that include dynamic recrystallization (e.g., Wenk and Tomé, 1999; Kaminski and Ribe, 2001), crystal nucleation and growth rates are varied so as to fit LPO evolution to the experimental observations. For example, 
the DRex model (Kaminski and Ribe, 2001, 2002) achieves a good fit to the experimental data and includes a parameterization to predict the time-scale for LPO evolution. These model predictions, however, are dependent on the validity of the extrapolation of the experimental data to the low strain rates that prevail in the mantle.

We present data from peridotite samples to test the extrapolation of experimental relationships for LPO development (Nicolas et al., 1973; Zhang and Karato, 1995; Bystricky et al., 2000) to natural conditions. Studies of deformation in naturally deformed peridotites are often hindered by the lack of a well-defined finite strain marker. However, the Josephine Peridotite is ideal for the analysis of fabric evolution with shear strain as it has a pre-existing foliation, defined by variations in pyroxene content, which provide a passive strain marker, as shown in Fig. 1. In addition, variations in pyroxene content permit assessment of the effects of second phases on olivine LPO development.

\section{Field observations}

The Josephine Peridotite in southwestern Oregon is the mantle section of a $\sim 150$ Ma ophiolite from a fore-arc or back-arc setting (Dick, 1976; Harper, 1984; Kelemen and Dick, 1995). The peridotite is predominantly composed of harzburgite, with pyroxene-rich layers in some localities (Dick and Sinton, 1979). A series of shear zones, described by Loney and Himmelberg (1976) and Kelemen and Dick (1995), outcrop over a distance of $300 \mathrm{~m}$ in the Fresno Bench area of the Josephine Peridotite. The shear zones are defined by the sub-vertical to vertical transposition of originally sub-horizontal lithological layering (Fig. 1). The narrowest, highest strain shear zones contain highly lineated orthopyroxene aggregates (Kelemen and Dick, 1995). The shear zones vary in width from $\sim 1 \mathrm{~m}$ to $60 \mathrm{~m}$ and exhibit right lateral displacement with a component of NW-down vertical movement (Kelemen and Dick, 1995). Foliations at shear zone centers strike 035-045 with a maximum dip of $90^{\circ}$ in the highest strain shear zones. 
Maximum temperatures during deformation are constrained by syn-deformational magmatic features. As outlined by Kelemen and Dick (1995), the shear zones may have initiated as regions of localized melt migration. Some of the shear zones cut or are cut by dunites, pyroxenites or gabbroic segregations, implying that temperatures during deformation may have been upwards of $\sim 1200^{\circ} \mathrm{C}$ (Kelemen and Dick, 1995). The lower temperature limit during deformation is constrained by geothermometry of coexisting pyroxene neoblast pairs in deformed harzburgites. Harding (1988) estimated a temperature range of $900-1100^{\circ}$, while Loney and Himmelberg (1976) estimated a temperature of $\sim 1000^{\circ}$, both from two pyroxene thermometry.

\section{Methods}

We analyzed olivine fabrics in harzburgites from the widest of the Josephine shear zones, shown in Fig. 1. The shear plane is approximately vertical, based on observations of how it cuts across topography along strike and the similar orientation of nearby shear zones with higher strains (Kelemen and Dick, 1995). Based on our field observations and those of Kelemen and Dick (1995), the shear plane is oriented at $035^{\circ} / 90^{\circ}$. The lineation plunge of $50^{\circ} \mathrm{NE}$ was determined from outcropscale observations of elongated orthopyroxene aggregates in a nearby, narrower, higher strain shear zone. Harzburgite and inter-layered dunite samples were collected on a NW-SE transect across the shear zone; the pyroxene layer orientation was measured wherever possible. In the geographic reference frame, the pyroxene layers dip $10^{\circ} \mathrm{SW}$ outside of the shear zone and reach a maximum dip of $75^{\circ} \mathrm{SW}$ at the shear zone center (Table 1).

A kinematic cross section of the shear zone is shown in Fig. 2A, oriented with the X-axis parallel to the shear direction and the $\mathrm{Z}$-axis normal to the shear plane. This $\mathrm{X}-\mathrm{Z}$ frame of reference is used for the remainder of the figures. For the cross section, the field data are rotated and projected onto the plane $305^{\circ} / 50^{\circ} \mathrm{NE}$, which lies perpendicular to the shear plane. In this kinematic reference frame, the pyroxene layers are oriented $78^{\circ}$ from the shear plane outside of the shear zone and are 
rotated to an angle of $10^{\circ}$ at the center of the shear zone. For fabric analyses, the Josephine samples were cut on the plane $305^{\circ} / 50^{\circ} \mathrm{NE}$. Thin sections were prepared with one edge parallel to $305^{\circ}$, so that all fabric data can be oriented with the $\mathrm{X}$-axis parallel to the shear direction and the Z-axis normal to the shear plane.

Strain across the shear zone is calculated from the change in pyroxene layer orientation in the kinematic reference frame, shown on the stereonet in Fig. 2B. Following the method of Ramsay and Graham (1970) and Ramsay (1980), shear strain, $\gamma$, is given by:

$$
\gamma=\cot \left(\alpha^{\prime}\right)-\cot (\alpha)
$$

where $\alpha$ is the initial angle of the pyroxene layering with respect to the shear plane and $\alpha^{\prime}$ is the deflection angle, as shown in Fig. 2C. Values for $\alpha^{\prime}$ and the orientation of the finite strain ellipse, $\theta^{\prime}$, are reported in Table 1 . Note that these values would only be the same if $\alpha=90$, in which case shear strain would be calculated directly from the cotangent of the deflection angle. A maximum shear strain of $525 \%$ is reached at the center of the shear zone. The shear zone is $50-60 \mathrm{~m}$ wide, with a total displacement across the shear zone of $60 \mathrm{~m}$, based on the area under a distance versus strain curve (Ramsay and Graham, 1970).

Olivine LPOs were measured on polished thin sections using a JEOL 840 SEM with an electron backscatter diffraction (EBSD) detector and HKL Technology's Channel 5 software package. Thin sections were prepared for analysis by polishing with $0.02 \mu \mathrm{m}$ colloidal silica for at least 2 hours. To limit charging during EBSD analysis, thin sections were coated with gold, then polished for one minute to remove gold from grain surfaces, while leaving gold along cracks and grain boundaries. Samples were mapped for orientations and mineral phases at 40x magnification and 40-100 $\mu \mathrm{m}$ step sizes. Between 24 and 48 overlapping maps were made per thin section and these were combined into a single image using the Channel 5 program MapStitcher.

EBSD maps (Fig. 3) have $\sim 50 \%$ indexed data, following rejection of all points with a mean 
angular deviation (MAD) number $\geq 1^{\circ}$. The MAD number quantifies the mismatch between lattice planes in a calculated orientation and lattice planes determined from bands in the digitized diffraction pattern. The MAD number provides an indication of data quality, with high numbers resulting from surface roughness and computer mis-indexing. Data were further processed by removing wild spikes and replacing these, and points with zero solutions, with the most common neighbor orientation. Wild spikes are single pixels (i) which are misoriented by $>10^{\circ}$ from the average orientation of the surrounding eight pixels and (ii) for which the maximum misorientation between any two of the surrounding eight pixels is $<10^{\circ}$. See Warren and Hirth (2006) for a more detailed discussion of our EBSD data processing techniques.

Pole figures and inverse pole figures, shown in Figs. 3-5, are calculated using one point per grain. Pole figures are equal area lower hemisphere projections and inverse pole figures are equal area upper hemisphere projections. All datasets contain $>200$ grains; Ben Ismaïl and Mainprice (1998) showed that $>100$ grain orientations are necessary to provide robust estimates of fabric pattern and strength. Grain boundaries are defined by misorientations $\geq 10^{\circ}$ between adjacent points and subgrains by $2^{\circ}-10^{\circ}$ misorientations.

Olivine grain size was measured by the line intercept method (Underwood, 1970) in three harzburgites, at $0 \%, 65 \%$ and $525 \%$ strain, and the dunite, as presented in Table 2. For consistency with the Van der Wal (1993) olivine piezometric data, we calculate the average grain size using the arithmetic mean. However, as shown in Fig. 6, the grain size distribution is approximately lognormal and the geometric mean, also given in Table 2, provides a more representative estimate of average grain size (Underwood, 1970). In addition, as noted by Drury (2005), different geometric correction factors for olivine grain size are used in different studies. For example, the olivine flow laws are based on a geometric correction factor of 1.5 (e.g., Hirth and Kohlstedt, 2003), whereas the Van der Wal (1993) piezometer uses a geometric correction factor of 1.75, following the method of Pickering (1976). 


\section{Results}

From analyses of nine samples across the Josephine shear zone, we find that the olivine [100] maximum, initially oriented at $62^{\circ}$ counterclockwise to the shear plane, is aligned parallel to the shear direction at the center of the shear zone. To visually demonstrate the change in olivine orientation with strain, EBSD orientation maps and inverse pole figures of a low strain and a high strain sample are shown in Fig. 3. Olivine is colored as a function of the angle between the [100] axis and the shear plane. In the $65 \%$ strain sample, the majority of grains are mid-blue in color, corresponding to a relatively high angle to the shear plane. In contrast, many grains in the 525\% strain sample are dark blue, indicating alignment with the shear plane.

The inverse pole figures in Fig. 3B show the orientation of individual grains with respect to the shear direction (X) and normal to the shear plane (Z). At 65\% strain, while considerable scatter exists in the distribution, the maximum density of points in the $\mathrm{X}$-section is oriented $37^{\circ}$ to [100]. In the Z-section, the maximum density is close to [001] with a low density around [010], suggesting that (001) is better aligned as the slip plane during the initial realignment of the fabric. At 525\% strain, the highest density of points in the $\mathrm{X}$-section is around [100]. In the Z-section, points cluster around [010] with scatter towards [001], indicating that both (010) and (001) are well oriented as slip planes.

Pole figures of olivine orientation are shown in Fig. 4 for the harzburgites and Fig. 5 for the dunite. Outside of the shear zone, the peridotite has a pre-existing LPO, with the olivine [100] maximum sub-parallel to the pre-existing foliation. In samples with shear strains up to $168 \%$, the olivine [100] maximum remains inclined to the shear plane, with only a moderate rotation away from the original LPO (Fig. 4). Between a shear strain of $168 \%$ and $258 \%$, the olivine LPO changes rapidly so that the [100] maximum is sub-parallel to the shear plane. At higher shear strains, the [100] maximum remains sub-parallel to the shear plane.

The behavior of olivine [010] and [001] axes with increasing strain is more variable than the 
[100] axis (Fig. 4). Outside of the shear zone, (010) planes are sub-parallel to the pyroxene layering, suggesting that (010) was the dominant slip plane during the previous deformation event. At low strain, (001) is sub-parallel to the local layering, suggesting that (001) is initially the dominant slip plane during the fabric realignment. However, at high strain, many grains have (010) sub-parallel to the transposed pyroxene layering. In addition, at high strain, [010] and [001] in the harzburgites exhibit girdles, whereas in the dunite they approximate single maxima (Fig. 5).

Inspection of the olivine pole figures in Fig. 4 also demonstrates that the variation in LPO among the samples does not simply reflect a rigid rotation of the pre-existing LPO. First, the evolution of the [010] and [001] pole figures clearly shows evidence for re-orientation of grains inconsistent with simple rotation. Second, the angle between the [100] maximum and the shear plane changes more rapidly than the angle between pyroxene banding and the shear plane. The [100] maximum is "back-tilted" from the banding at shear strains of $118 \%$ and $131 \%$. It then "rotates through" the banding between $131 \%$ and $258 \%$ shear strain (Fig. 4).

Grain size and shape in harzburgites outside and inside the shear zone are similar, as demonstrated by the grain size distributions in Fig. 6. Harzburgites have a mean grain size in the range 0.7-0.8 mm, whereas the dunite has a larger grain size of $1.1 \mathrm{~mm}$ (Table 2). These values are calculated using the arithmetic mean followed by a correction factor of 1.75 , for consistency with the olivine piezometer (Van der Wal et al., 1993). The grain size distributions in Fig. 6B are approximately log-normal, with recrystallization resulting in deviations from the log-normal distribution at small grain sizes $(<0.5 \mathrm{~mm})$. In the low strain harzburgite, pyroxenes are slightly elongated, with their long axes approximately aligned with the pyroxene layering and the olivine [100] maximum. Olivine grains are generally equant, with an aspect ratio (X:Z) of 1.1. In the high strain sample, both orthopyroxenes and olivines are equant, with an olivine aspect ratio of 1.2.

In Fig. 7, we show photomicrographs of samples at low and high strain to demonstrate the microstructural characteristics of the peridotites. Large olivine grains often contain subgrain boundaries and interpenetrating olivine grain boundaries indicate grain boundary migration, both at low 
and high strain. Overall, as with the grain size distributions, we do not observe a significant variation in grain-scale microstructure across the shear zone.

The change in the angle of the olivine [100] maximum relative to the shear plane with increasing strain is compared to experimental results and models in Fig. 8. The angle of the olivine axis maximum relative to the shear plane was determined using the eigenvector analysis provided by the program PFch5.app (courtesy of D. Mainprice). The results of this analysis are provided in Table 3. The first eigenvector of the orientation tensor represents the mean direction of a crystal axis and is called the principal axis (Woodcock, 1977). We assume that this principal axis is more representative of the average [100] orientation than the location of the maximum density of data on the pole figure. In comparison to experiments, the Josephine samples are observed to require higher strain to align with the shear direction.

LPO strength was quantified using the J-index (Bunge, 1982; Mainprice and Silver, 1993) and the M-index (Skemer et al., 2005), both of which are plotted as a function of strain in Fig. 9 and given in Table 3. In addition, we plot the published J-index values for the experimental datasets and models. Both indices quantify overall fabric strength by combining data for all three olivine axes. The M-index quantifies the deviation of the uncorrelated misorientation angle distribution from a random misorientation distribution (Skemer et al., 2005). Uncorrelated misorientation angles represent the angular difference in orientation (i.e., misorientation) between random grain pairs (i.e., not necessarily adjacent). The $\mathrm{M}$-index varies between 0 for a random fabric and 1 for a single crystal. The J-index is a dimensionless characterization of the orientation distribution function (ODF) of crystal orientations as specified by Euler angles. It describes the distribution of Euler angle rotations away from a single crystal orientation, varying between 1 for a random LPO and infinity for a single crystal. In practice, the J-index has a maximum value of 250 , as the ODF is truncated at degree 22. For our J-index calculations, we used the program SuperJctf.app (courtesy of D. Mainprice) with a $10^{\circ}$ Gaussian half-width, data clustered in $1^{\circ}$ bins and combined even and odd spherical harmonics. 
In the Josephine samples, neither the M-index nor the J-index demonstrate a significant increase in fabric strength with strain. The J-index is relatively constant as a function of shear strain and is generally in the range 5-8. The M-index initially increases in strength but is then relatively constant with an average value of 0.14 . The only exception is the $386 \%$ strain harzburgite, which has a visibly weaker fabric in the pole figure (Fig. 4) and the lowest J- and M-index values. In Fig. 10, we compare the M-index to the J-index; a linear least squares regression through the dataset produces a reasonable correlation with a correlation coefficient of 0.7 . The two indices cannot be directly related as they are based on different parameterizations of crystal orientation.

\section{Discussion}

Our results on olivine LPO evolution during simple shear extend observations of LPO variations to lower stresses and strain rates than are available from experimental datasets (Zhang and Karato, 1995; Bystricky et al., 2000). While our observations broadly agree with the experimental data, our results suggest that a pre-existing LPO influences the strain necessary for LPO alignment with the shear direction. In addition, the pre-existing LPO and presence of additional phases affect the behavior of olivine slip systems during deformation.

The orientation of the olivine [100] maximum as a function of shear strain in the Josephine shear zone is compared to the experimental datasets and models in Fig. 8. The experiments and models initially have a random fabric. In contrast, the Josephine sample from outside the shear zone, used as a reference for zero strain, was previously deformed. This sample has an LPO with a J-index of 6.2 and a [100] maximum oriented $62^{\circ}$ from the shear direction. In our natural samples, the [100] maximum does not align with the shear direction until $~ 250 \%$ strain, whereas alignment occurs before $200 \%$ strain in the Bystricky et al. (2000) experiments and at $\sim 150 \%$ strain in the Zhang and Karato (1995) experiments. Below, we compare our results in more detail to LPO evolution models and discuss the effects of a pre-existing LPO, grain size and additional phases on 
the behavior of olivine during deformation in the upper mantle.

\subsection{Comparison to LPO evolution models}

As a tool for predicting and interpreting seismic anisotropy, various theoretical models predict olivine LPO evolution during deformation (e.g., Etchecopar and Vasseur, 1987; Wenk and Tomé, 1999; Tommasi et al., 2000; Kaminski and Ribe, 2002; Blackman et al., 2002). The evolution of the olivine [100] axis with strain is shown for four models in Fig. 8. Two are end-member models for which the olivine LPO is assumed to follow either the shear direction or the finite strain ellipsoid (McKenzie, 1979; Ribe, 1992). The experimental datasets (Nicolas et al., 1973; Zhang and Karato, 1995; Bystricky et al., 2000) demonstrate that these end-member models do not accurately predict the evolution of olivine LPOs with shear strain, and the Josephine data support this conclusion. The best fits of the VPSC (Tommasi et al., 2000) and DRex (Kaminski and Ribe, 2001) models to the Zhang and Karato experiments are also shown in Fig. 8.

The VPSC model treats each grain in an aggregate as an inclusion embedded in a homogeneous effective medium (Lebensohn and Tomé, 1993). The average stress and strain rate for each grain is constrained by the macroscopic deformation, grain orientation and assumptions regarding strain compatibility. A reasonable match of VPSC pole figures to experimental pole figures is achieved by relaxing the requirement for strain compatibility. However, the [100] maximum does not align with the shear direction at as low a strain as that observed in either the experiments or the natural samples. The VPSC curve shown in Fig. 8 is for a model run to $350 \%$ shear strain with a dimensionless strain compatibility value of $\alpha=100$ (a relatively relaxed compatibility requirement). Linear extrapolation to higher strain suggests that the [100] maximum might align with the shear direction by $\sim 1000 \%$ shear strain. However, this version of the VPSC model is not well constrained at $>100 \%$ strain, as it does not account for complexities associated with highly deformed grains (Blackman et al., 2002) or recrystallization. Intriguingly, the 2D kinematic model of Etchecopar and Vasseur (1987), which is based on a minimization of strain incompatibility, pro- 
duces a [100] maximum aligned with the shear plane at relatively low strain. In this model, fast reorientation of the dominant slip system is obtained by a recrystallization procedure that allows periodic relaxation of the strain compatibility constraint by resetting all grain shapes to spheres.

To obtain a better match to experimental data, Wenk and Tomé (1999), Kaminski and Ribe (2001) and Blackman et al. (2002) have all developed models that include dynamic recrystallization. In these models, recrystallization is treated as a balance of grain boundary migration (relatively undeformed grains replace highly deformed grains) and grain nucleation (highly deformed grains nucleate strain-free subgrains with the same orientation). DRex (Kaminski and Ribe, 2001) predicts the deformation of an olivine aggregate by defining a local velocity gradient tensor for each grain and a macroscopic velocity gradient tensor. A good fit to the experimental data is provided by optimizing the dimensionless grain boundary migration $\left(M^{*}\right)$ and grain nucleation $\left(\lambda^{*}\right)$ parameters. For $M^{*}=200$ and $\lambda^{*}=5$, the [100] maximum aligns with the flow direction by $100 \%$ strain, as shown in Fig. 8, and pole figures are in good agreement with the Zhang and Karato experiments.

In regions where the kinematics of deformation evolve, the rate at which LPO changes also has important implications for the interpretation of seismic anisotropy. For example, during corner flow under ridges and subduction zones, olivine grains will experience a change in the orientation of the strain field during deformation. The latest version of DRex (Kaminski and Ribe, 2002; Kaminski et al., 2004) includes a parameterization of the rate at which LPO re-aligns with the flow direction. This parameterization derives from the concept of the infinite strain axis (ISA), which is defined as the asymptotic orientation of the long axis of the finite strain ellipsoid. Kaminski and Ribe (2002) suggested that the olivine a-axis orientation coincides with the ISA after sufficient strain, following the experimental results from Zhang and Karato (1995). However, the ISA is only a good approximation for the LPO if re-orientation of the olivine LPO toward the ISA is faster than variation of the ISA along mantle flow lines. To quantify this effect, Kaminski and Ribe (2002) defined the "grain orientation lag" parameter as the ratio of the time-scale for LPO rotation toward 
the ISA to the time-scale for ISA re-orientation along flow lines. At face value, the rate of change of LPO with strain in our samples is similar to that predicted by DRex models with $M^{*}=200$ and $\lambda^{*}=5$. In this case, comparison with the models presented by Kaminski and Ribe (2002) suggests that the ISA provides a good estimate for the orientation of olivine LPO in regions away from plate boundaries. This conclusion is supported by a recent comparison of observed shear wave splitting measurements to anisotropy predicted from global flow models that incorporate the orientation lag concept (Conrad et al., 2007).

In detail, the Josephine shear zone data do not agree with predictions from either the VPSC or DRex models, which were both optimized to fit the Zhang and Karato experiments (Fig. 8). The transition to a shear aligned fabric in the Josephine harzburgites occurs at significantly lower strain than predicted by VPSC without recrystallization. The rotation of the [100] axis between $168 \%$ and $258 \%$ shear strain occurs at a rate similar to that predicted by the DRex model. However, the change occurs at higher shear strain for the Josephine samples, which is likely due to the initially strong LPO.

\subsection{Active slip systems and the pre-existing LPO}

We suggest that the presence of a pre-existing LPO influences the amount of strain necessary for the [100] maximum to rotate into the shear plane. In addition, we suggest that the orientation of the pre-existing LPO is important in controlling slip system activity during the initial stages of deformation. At high strain, the LPO indicates that deformation is dominantly accommodated by slip on (010)[100] and (001)[100], the easiest slip systems for olivine (e.g., Bai et al., 1991). In contrast, evolution of the LPO at strains less than $131 \%$ suggests that slip on (001)[100] dominates. This system has been interpreted to dominate in olivine under low stress conditions in the presence of moderate water contents (Mehl et al., 2003; Katayama et al., 2004). However, as the high strain samples show strong evidence for slip on (010)[100], we conclude that the initial dominance of (001)[100] slip is due to the influence of the pre-existing LPO. 
In the kinematic reference frame of the shear zone, the pre-existing [010] maximum indicates that the (010) planes were initially oriented roughly perpendicular to the shear plane (Fig. 4). By contrast, the (001) planes were initially better oriented for deformation on the shear plane. As shown in Fig. 4, a significant fraction of grains have (001) planes oriented roughly parallel $\left(\sim 14^{\circ}\right)$ to the shear plane. In comparison to the LPO evolution models, we also emphasize that the [100] maximum does not begin to rotate rapidly into the shear plane until a significant number of grains have become well oriented for slip on (010)[100], at shear strains between $161 \%$ and 258\% (Fig. 4). The [100] maximum was initially $62^{\circ}$ from the shear direction and thus poorly oriented for slip in the shear zone. Hence, the orientation of the pre-existing LPO appears to control slip system activation and the strain necessary for LPO re-alignment.

\subsection{LPO Strength}

The evolution of fabric strength with strain is also important for constraining models of LPO formation. In Fig. 9, the strengths of Josephine LPOs are compared to experimental datasets and model predictions. Fabric strengths of the Zhang and Karato samples deformed at $1200^{\circ} \mathrm{C}$ are similar to those of the Josephine samples, whereas the high strain $1300^{\circ} \mathrm{C}$ experiments have significantly higher J-indices than the Josephine samples. Comparison of the pole figures for the high temperature experiments (Zhang et al., 2000) to the Josephine samples reveals that the strengths of the [100] peaks are similar, but that the experimental samples have much stronger [010] and [001] maxima. Hence, the rapid increase in J-index with shear strain observed in the experiments results from alignment of the [010] and [001] axes. In the Josephine samples, [010] and [001] tend to have girdled patterns, leading to lower J-indices.

The high strain torsion experiments of Bystricky et al. (2000) also demonstrate an increase in J-index with strain, but at a lower rate than observed in the Zhang and Karato experiments. The maximum J-index observed for the Bystricky et al. samples is similar to the maximum value observed for the Josephine samples. However, the results of the Bystricky et al. experiments 
suggest that fabric strength continues to increase at shear strains $\geqslant 500 \%$, whereas no such increase is apparent for the Josephine samples. Clearly the evolution of fabric strength at low strain is influenced by the presence of the pre-existing LPO in the natural samples. Another variable that has not been evaluated in experimental studies is the role of pyroxene.

Both DRex and VPSC models predict rapidly increasing fabric strength with shear strain. The models initially have a random fabric and hence the fabric strength increases significantly at low strain when an LPO forms. However, the continued increase in the models does not match our observations or most experimental results. Thus the models do not account for all processes occurring during deformation. Inclusion of orthopyroxene produces modest increases in fabric strength for VPSC models (Wenk et al., 1991; Blackman et al., 2002) and somewhat weaker fabric strengths in DRex (Kaminski et al., 2004). The increase in fabric strength with strain in DRex is also decreased in the more recent version that includes grain boundary sliding (Kaminski et al., 2004).

Overall, we observe lower LPO strengths than predicted by the theoretical models. The match is better for the experimental datasets, with the exception of the high temperature, high strain experiments of Zhang and Karato (1995). These differences indicate that the models do not replicate all aspects of the natural environment. However, seismic properties are only weakly dependent on LPO intensity (e.g., Tommasi et al., 2000). For the interpretation of seismic anisotropy, understanding the rate at which olivine aligns with the shear direction is more important than the fabric strength which is produced.

\subsection{Grain size and recrystallization}

As discussed above, theoretical models suggest that dynamic recrystallization plays an important role in LPO evolution. In the Josephine, the amount of strain accommodated in the shear zone and the absence of stretched grains indicates that dynamic recrystallization occurred during deformation. Our analyses, shown in Fig. 6, indicate that olivine grain size in the harzburgites remains relatively constant during strain localization. Inside and outside the shear zone, the grain size is 
$\sim 0.7-0.8 \mathrm{~mm}$, with nearly equant olivine grains. These results suggest that the deformation event that produced the pre-existing LPO resulted in a recrystallized grain size similar to that produced during shear zone deformation.

In the high strain experiments (Zhang and Karato, 1995; Zhang et al., 2000; Bystricky et al., 2000), the recrystallized grain sizes are significantly smaller than the initial grain size. Furthermore, the experimental samples never fully recrystallize, as indicated by the presence of elongate, relict porphyroclasts (Lee et al., 2002). We suggest that the preservation of elongate porphyroclasts in the experimental samples reflects the large contrast between the initial and steady-state recrystallized grain size. Importantly, the analysis of Lee et al. (2002) also indicates that the high dislocation density relict porphyroclasts maintain the shear-aligned orientation.

Recrystallized grain size can be used to estimate stress during deformation (Karato et al., 1980; Van der Wal et al., 1993). The similar grain size of the low and high strain samples from the Josephine suggests that stress remained relatively constant during formation of the shear zone. In addition, stress must be continuous across the shear zone. Using the olivine grain size piezometer and the grain size of the Josephine dunite $(\sim 1.1 \mathrm{~mm})$, we estimate a stress of $\sim 7 \mathrm{MPa}$ during deformation, as shown in Fig. 11. The high strain experimental datasets (Zhang et al., 2000; Bystricky et al., 2000) are also plotted in Fig. 11. The grain size measurements from Zhang et al. (2000) have been adjusted to the same geometrical correction factor as the Van der Wal piezometric dataset (Van der Wal, 1993) and show reasonable agreement with the piezometer (which was calibrated using lower strain experiments). At a stress of $7 \mathrm{MPa}$, olivine flow laws (Hirth and Kohlstedt, 2003) predict a strain rate of approximately $10^{-12} \mathrm{~s}^{-1}$ at temperatures of $1100^{\circ} \mathrm{C}$ (dry conditions) or $1000^{\circ} \mathrm{C}$ (wet conditions, with an olivine water content of $200 \mathrm{H} / 10^{6} \mathrm{Si}$, which is below that required to induce a transition to an "E-type" fabric (Katayama et al., 2004)). For context, given the width of the Josephine shear zone, strain rates in the range of $10^{-12} \mathrm{~s}^{-1}$ require tectonic displacement rates on the order of a few mm/year.

In the experimental datasets (Zhang and Karato, 1995; Bystricky et al., 2000), a secondary 
maximum is observed with the olivine [100] axis aligned perpendicular to the principle compressive stress. Lee et al. (2002) showed that the secondary peak originated from the growth of grains that were poorly oriented for slip. These grains grow by grain boundary migration at the expense of well-oriented grains that have developed high dislocation densities - a process also captured in theoretical models that include recrystallization (Wenk and Tomé, 1999; Kaminski and Ribe, 2001). A similar secondary maximum in the LPO is not observed in the Josephine samples (Figs. 4 and 5). The important role of grain boundary migration in the experiments is likely due to the higher differential stress, which results in a larger driving force for grain boundary migration. These driving forces are much lower under natural conditions.

In the DRex model, the parameter $M^{*}$ controls grain boundary mobility during LPO formation. When $M^{*}=0$, the LPO predicted by DRex aligns with the finite strain ellipsoid. For $M^{*}>0$, the olivine [100] maximum aligns with the shear direction, with decreasing amounts of shear strain necessary for alignment as $M^{*}$ increases. The best fit of DRex to the $1300^{\circ} \mathrm{C}$ Zhang and Karato experimental data is achieved when $M^{*}=200$, as shown in Fig. 8. The strain at which [100] aligns in the Josephine samples is consistent with an $M^{*}$ value of $\sim 50$. However, Kaminski and Ribe (2001) also found a secondary [100] maximum with $M^{*}=50$, which is not observed in the samples from the Josephine.

\subsection{Effect of additional phases}

Based on a combination of experimental and theoretical studies, we speculate that differences in the LPO of dunites and harzburgites arise from enhancement of grain boundary sliding in harzburgites due to the presence of orthopyroxene. The high strain Josephine harzburgite samples exhibit [010] and [001] girdles, whereas the high strain dunite has stronger point maxima (Figs. 4-5). Similar observations have been made for adjacent harzburgite/dunite samples from the Oman ophiolite (Braun, 2004). In both cases, the harzburgites are observed to be finer grained than the adjacent dunites, suggesting grain growth during recrystallization is limited by the second phase (Warren 
and Hirth, 2006). Smaller grain sizes enhance deformation by dislocation accommodated grain boundary sliding (DisGBS in the nomenclature of Warren and Hirth, 2006).

In the study by Bystricky et al. (2000), high strain fabrics are characterized by [010] and [001] girdles, as observed in the Josephine harzburgites. By contrast, in the lower stress - and somewhat lower strain - Zhang and Karato (1995) experiments, a [010] maximum is observed perpendicular to the shear plane in relict grains (Zhang et al., 2000), similar to the Josephine dunite. Bystricky et al. (2000) concluded that girdles formed owing to higher strain. However, grain size evolution may play a more important role than strain alone. As emphasized by Drury (2005), the original grain size of the samples deformed by Zhang and Karato was $\sim 40-50 \mu \mathrm{m}$, large enough to suppress a significant contribution from DisGBS at the beginning of the experiment, based on olivine flow laws (Hirth and Kohlstedt, 2003). By contrast, the recrystallized grain size ( $\sim 5 \mu \mathrm{m})$ of the Bystricky et al. samples is well within the DisGBS regime. SEM analyses of the recrystallized matrix of the Zhang and Karato samples also provide qualitative evidence for grain boundary sliding at higher strain (Lee et al., 2002).

The hypothesis that the LPO girdle forms owing to DisGBS is also supported by theoretical studies. The insight here is based on consideration of the critical resolved shear stress for slip on different olivine systems. While (010)[100] is generally assumed to be the easiest slip system, single crystal data demonstrate that the critical resolved shear stresses for (010)[100] and (001)[100] are the same within error, at $\sim 1100-1250^{\circ} \mathrm{C}$ under dry conditions (Bai et al., 1991). To accommodate the von Mises strain compatibility criterion (von Mises, 1928), slip on the "hard" system (010)[001] is also required. The Tommasi et al. (2000) VPSC models show that when hard slip is required, the LPO is dominated by the (010)[100] because slip on (010)[001] results in grain rotations that favor slip on (010)[100] relative to (001)[100]. However, if strain compatibility constraints are relaxed (e.g., using the $\alpha$ parameter in the Tommasi et al. models), a more girdled pattern is observed, associated with limited activity of (010)[001]. Following Braun (2004), we propose that DisGBS relaxes the requirement for (010)[001] slip, allowing the easy slip systems to 
operate together to produce the [010] and [001] girdles.

\section{Conclusions}

Our results on olivine LPO evolution during shear are consistent with the conclusion from experimental data (Nicolas et al., 1973; Zhang and Karato, 1995; Bystricky et al., 2000) that olivine LPO aligns with the shear direction during deformation. However, alignment of naturally deformed samples requires higher strain, which we suggest is due to the orientation of the pre-existing LPO. Our results extend the observations of how olivine LPO evolves within simple deformation kinematics to lower stress and strain rate conditions in the earth.

\section{Acknowledgments}

This work benefited from discussions with M. Behn, L. Montési, H.J.B. Dick, A. Tommasi, É. Kaminski, L. Mehl and J. Tullis. H.J.B. Dick provided insight in the field. K. Hanghøj, M. Billen, B. deMartin, L. Montési, M. Sundberg and R. Workman helped with fieldwork. Early work by S. Singletary provided initial results on LPO variation across the shear zone. We thank L. Kerr at the Marine Biological Laboratory for keeping the SEM in operating condition. A. Tommasi and É. Kaminski kindly shared results from their model calculations. We are grateful to D. Mainprice for providing his software for plotting pole figures and calculating fabric strengths. Finally, we thank A. Tommasi and an anonymous reviewer for their thoughtful reviews. This work was partly supported by NSF grants EAR-0230267 and EAR-0409609. Funding for fieldwork was provided by the WHOI Academic Programs Office as part of a 2003 field class run by P.B.K. and G.H. 


\section{References}

Bai, Q., Mackwell, S. J., Kohlstedt, D. L., 1991. High-temperature creep of olivine single crystals 1. Mechanical results for buffered samples. Journal of Geophysical Research 96 (B2), 24112463.

Ben Ismaïl, W., Mainprice, D., 1998. An olivine fabric database: an overview of upper mantle fabrics and seismic anisotropy. Tectonophysics 296, 145-157.

Blackman, D. K., Kendall, J. M., 2002. Seismic anisotropy in the upper mantle: 2. Predictions for current plate boundary flow models. Geochemistry, Geophysics, and Geosystems 3 (9), 10.1029/2001GC000247.

Blackman, D. K., Wenk, H. R., Kendall, J. M., 2002. Seismic anisotropy of the upper mantle: 1. Factors that affect mineral texture and effective elastic properties. Geochemistry, Geophysics, and Geosystems 3 (9), 10.1029/2001GC000248.

Braun, M. G., 2004. Petrologic and microstructural constraints on focused melt transport in dunites and the rheology of the shallow mantle. Ph.D. thesis, MIT/WHOI Joint Program.

Bunge, H. J., 1982. Texture Analysis in Materials Sciences. Butterworths, London.

Bystricky, M., Kunze, K., Burlini, L., Burg, J.-P., 2000. High shear strain of olivine aggregates: Rheological and seismic consequences. Science 290, 1564-1567.

Conrad, C. P., Behn, M. D., Silver, P. G., 2007. Global mantle flow and the development of seismic anisotropy: Differences between the oceanic and continental upper mantle. Journal of Geophysical Research 112, 10.1029/2006JB004608.

Dick, H. J. B., 1976. Origin and emplacement of the Josephine Peridotite of southwestern Oregon. Ph.D. thesis, Yale University.

Dick, H. J. B., Sinton, J. M., 1979. Compositional layering in alpine peridotites: Evidence for pressure solution creep in the mantle. Journal of Geology 87, 403-416.

Drury, M. R., 2005. Dynamic recrystallization and strain softening of olivine aggregates in the laboratory and the lithosphere. In: Gapais, D., Brun, J. P., Cobbold, P. R. (Eds.), Deformation Mechanisms, Rheology and Tectonics: from Minerals to the Lithosphere. No. 243 in Special Publication. Geological Society of London, pp. 143-158.

Durham, W. B., Goetze, C., 1977. Plastic flow of oriented single crystals of olivine 1. mechanical data. Journal of Geophysical Research 82 (36), 5737-5753.

Etchecopar, A., Vasseur, G., 1987. A 3-D kinematic model of fabric development in polycrystalline aggregates: comparisons with experimental and natural examples. Journal of Structural Geology $9(5 / 6), 705-717$. 
Grimmer, H., 1979. The distribution of disorientation angles if all relative orientations of neighbouring grains are equally probable. Scripta Metallurgica 13, 161-164.

Harding, D. J., 1988. Josephine peridotite tectonites: A record of upper-mantle plastic flow (Klamath Mountains, Oregon). Ph.D. thesis, Cornell University.

Harper, G. D., September 1984. The Josephine ophiolite, northwestern California. Geological Society of America Bulletin 95, 1009-1026.

Hess, H. H., 1964. Seismic anisotropy of the uppermost mantle under oceans. Nature 203 (4945), 629-631.

Hirth, G., Kohlstedt, D. L., 2003. Rheology of the upper mantle and the mantle wedge: A view from the experimentalists. In: Eiler, J. (Ed.), The Subduction Factory. Vol. 138 of Geophysical Monograph. American Geophysical Union, pp. 83-105.

Kaminski, É., Ribe, N. M., 2001. A kinematic model for recrystallization and texture development in olivine polycrystals. Earth and Planetary Science Letters 189, 253-267.

Kaminski, É., Ribe, N. M., 2002. Timescales for the evolution of seismic anisotropy in mantle flow. Geochemistry, Geophysics, and Geosystems 3 (8), 10.1029/2001GC000222.

Kaminski, É., Ribe, N. M., Browaeys, J. T., 2004. D-Rex, a program for calculation of seismic anisotropy due to crystal lattice preferred orientation in the convective upper mantle. Geophysical Journal International 158, 744-752.

Karato, S.-I., 1992. On the Lehmann discontinuity. Geophysical Research Letters 19 (22), 22552258.

Karato, S.-I., Toriumi, M., Fujii, T., 1980. Dynamic recrystallization of olivine single crystals during high-temperature creep. Geophysical Research Letters 7 (9), 649-652.

Katayama, I., Jung, H., Karato, S.-I., 2004. New type of olivine fabric from deformation experiments at modest water content and low stress. Geology 32 (12), 1045-1048.

Kelemen, P. B., Dick, H. J. B., 1995. Focused melt flow and localized deformation in the upper mantle: Juxtaposition of replacive dunite and ductile shear zones in the Josephine peridotite, SW Oregon. Journal of Geophysical Research 100 (B1), 423-438.

Lebensohn, R. A., Tomé, C. N., 1993. A self-consistent anisotropic approach for the simulation of plastic deformation and texture development of polycrystals: Application to zirconium alloys. Acta Metallurgica et Materialia 41 (9), 2611-2624.

Lee, K.-H., Jian, Z., Karato, S.-I., 2002. A scanning electron microscope study of the effects of dynamic recrystallization on lattice preferred orientation in olivine. Tectonophysics 351, 331341. 
Loney, R. A., Himmelberg, G. R., 1976. Structure of the Vulcan Peak alpine-type peridotite, southwestern Oregon. Geological Society of America Bulletin 87, 259-274.

Mainprice, D., Silver, P. G., 1993. Interpretation of SKS-waves using samples from the subcontinental lithosphere. Physics of the Earth and Planetary Interiors 78, 257-280.

Mainprice, D., Tommasi, A., Couvy, H., Cordier, P., Frost, D. J., 2005. Pressure sensitivity of olivine slip systems and seismic anisotropy of Earth's upper mantle. Nature 433, 731-733.

McKenzie, D., 1979. Finite deformation during fluid flow. Geophysical Journal of the Royal Astronomical Society 58, 689-715.

Mehl, L., Hacker, B. R., Hirth, G., Kelemen, P. B., 2003. Arc-parallel flow within the mantle wedge: Evidence from the accreted Talkeetna arc, south central Alaska. Journal of Geophysical Research 108 (B8), 10.1029/2002JB002233.

Nicolas, A., Boudier, F., Boullier, A. M., 1973. Mechanisms of flow in naturally and experimentally deformed peridotites. American Journal of Science 273, 853-876.

Nicolas, A., Christensen, N. I., 1987. Formation of anisotropy in upper mantle peridotites - A review. In: Fuchs, K., Froidevaux, C. (Eds.), Composition, Structure and Dynamics of the Lithosphere-Asthenosphere System. Vol. 16 of Geodynamics Series. American Geophysical Union, pp. 111-123.

Pickering, F. B., 1976. The basis of quantitative metallography. Institute of Metallurgical Technicians, London.

Ramsay, J. G., 1980. Shear zone geometry: a review. Journal of Structural Geology 2 (1/2), 83-99.

Ramsay, J. G., Graham, R. H., 1970. Strain variation in shear belts. Canadian Journal of Earth Sciences 7, 786-813.

Ribe, N. M., 1992. On the relation between seismic anisotropy and finite strain. Journal of Geophysical Research 97 (B6), 8737-8747.

Ribe, N. M., Yu, Y., 1991. A theory for plastic deformation and textural evolution of olivine polycrystals. Journal of Geophysical Research 96 (B5), 8325-8335.

Skemer, P., Katayama, I., Jiang, Z., Karato, S.-I., 2005. The misorientation index: Development of a new method for calculating the strength of lattice-preferred orientation. Tectonophysics 411, $157-167$.

Tommasi, A., Mainprice, D., Canova, G., Chastel, Y., 2000. Viscoplastic self-consistent and equilibrium-based modeling of olivine lattice preferred orientations: Implications for the upper mantle seismic anisotropy. Journal of Geophysical Research 105 (B4), 7893-7908.

Underwood, E. E., 1970. Quantitative Stereology. Addison-Wesley, Reading, Massachusetts. 
Van der Wal, D., 1993. Deformation processes in mantle peridotites. Ph.D. thesis, Utrecht, Geologica Ultraiectina 102.

Van der Wal, D., Chopra, P., Drury, M., Fitz Gerald, J., 1993. Relationships between dynamically recrystallized grain size and deformation conditions in experimentally deformed olivine rocks. Geophysical Research Letters 20 (14), 1479-1482.

von Mises, R., 1928. Mechanik der plastischen formanderung von kristallen. Zeitschrift für Angewandte Mathematik und Mechanik 8 (3), 161-185.

Warren, J. M., Hirth, G., 2006. Grain size sensitive deformation mechanisms in naturally deformed peridotites. Earth and Planetary Science Letters 248, 423-435.

Wenk, H.-R., 2002. Texture and anisotropy. In: Karato, S.-i., Wenk, H.-R. (Eds.), Plastic Deformation of Minerals and Rocks. Vol. 51 of Reviews in Mineralogy and Geochemistry. Mineralogical Society of America, pp. 291-329.

Wenk, H. R., Bennett, K., Canova, G. R., Molinari, A., 1991. Modelling plastic deformation of peridotite with the self-consistent theory. Journal of Geophysical Research 96 (B5), 8337-8349.

Wenk, H. R., Tomé, C. N., 1999. Modeling dynamic recrystallization of olivine aggregates deformed in simple shear. Journal of Geophysical Research 104 (B11), 25513-25527.

Woodcock, N. H., 1977. Specification of fabric shapes using an eigenvalue method. Geological Society of America Bulletin 88, 1231-1236.

Zhang, S., Karato, S.-I., 1995. Lattice preferred orientation of olivine aggregates deformed in simple shear. Nature 375, 774-777.

Zhang, S., Karato, S.-I., Fitz Gerald, J., Faul, U. H., Zhou, Y., 2000. Simple shear deformation of olivine aggregates. Tectonophysics 316, 133-152. 


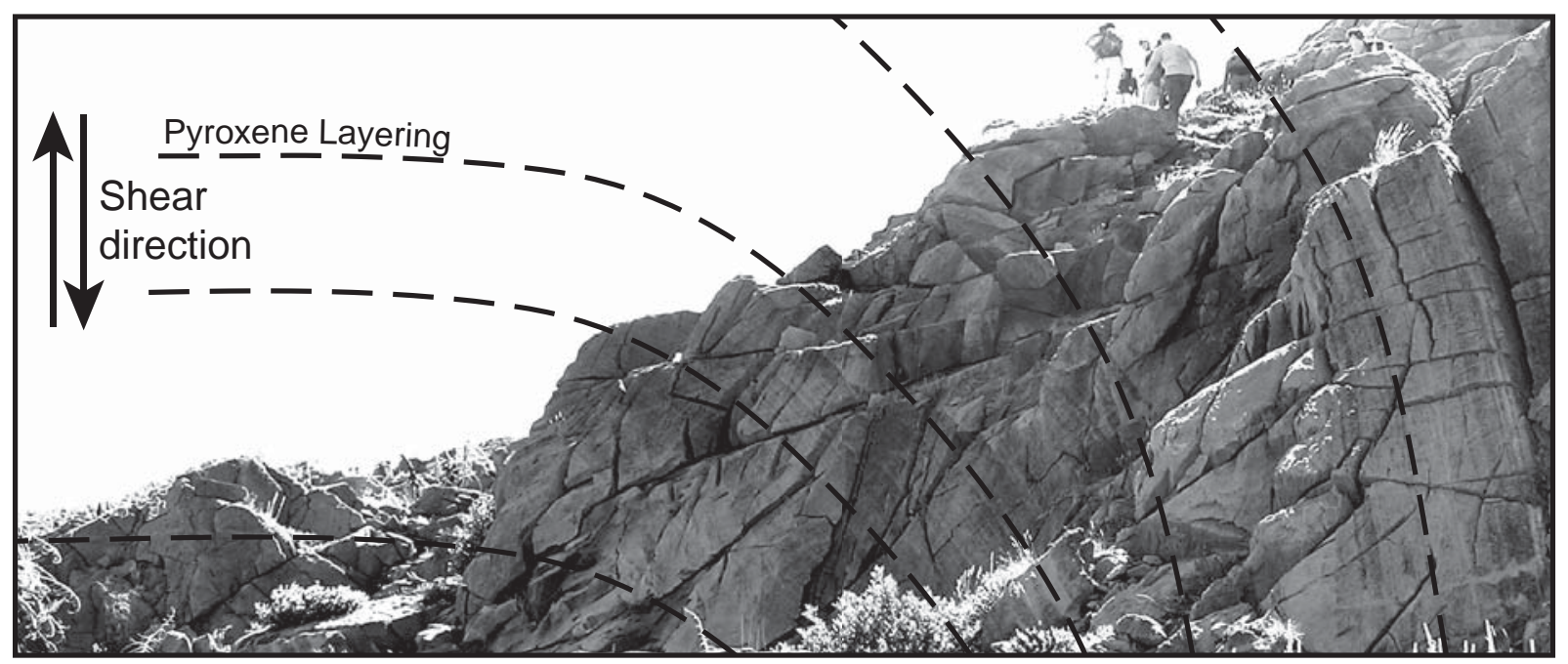

Figure 1: Photo of deformed layers in a Josephine shear zone, with the trace of the pyroxene layers outlined. Deflection of the regional pyroxene layering by right lateral shear provides a passive marker of strain. 

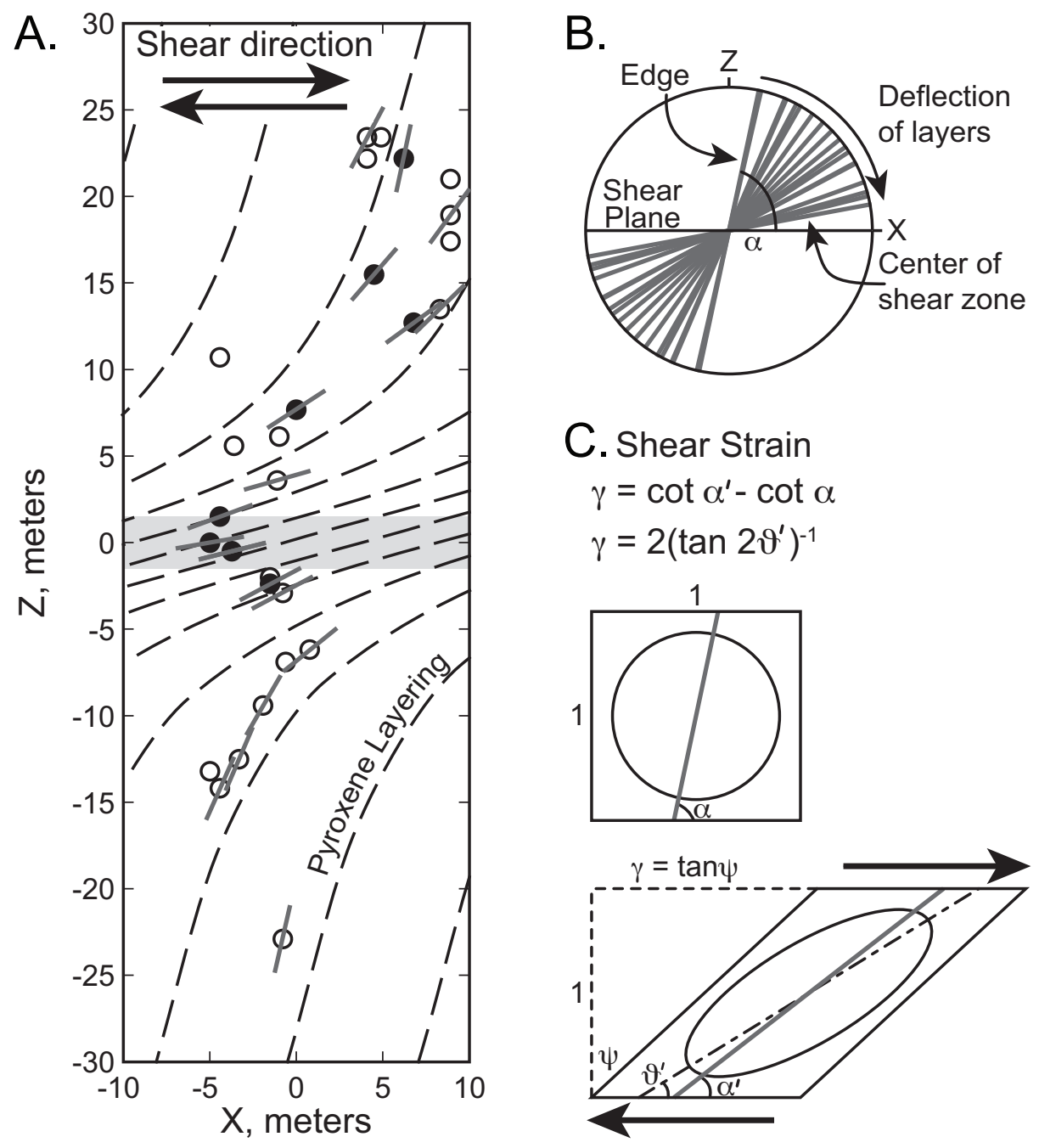

Figure 2: (A) $\mathrm{X}-\mathrm{Z}$ cross-section of the shear zone constructed from field data of sample locations and the strike and dip of pyroxene layers. This map is in the kinematic reference frame, perpendicular to the shear plane and parallel to the shear lineation, represented by the plane $305^{\circ} / 50^{\circ}$. Circles indicate sample locations, with analyzed samples indicated by filled circles. Measured pyroxene layer orientations are shown by the short grey lines. (B) Stereonet of the variation of pyroxene layer orientations with respect to the shear plane. To represent the true deflection of a passive strain marker by shear deformation, the data have been rotated and projected onto the plane perpendicular to the shear plane, as in the map cross-section. The angle $\alpha$ is the initial angle of the pyroxene layering outside the shear zone. (C) The geometric relationship of shear strain, $\gamma$, to the orientation of a marker layer, which initially lies at an angle $\alpha$ to the shear plane and is deflected to a smaller angle, $\alpha^{\prime}$. The orientation of the finite strain ellipsoid long axis is represented by the angle $\theta^{\prime}$ and is not coincident with the marker layer. Diagram adapted from Ramsay and Graham (1970). 


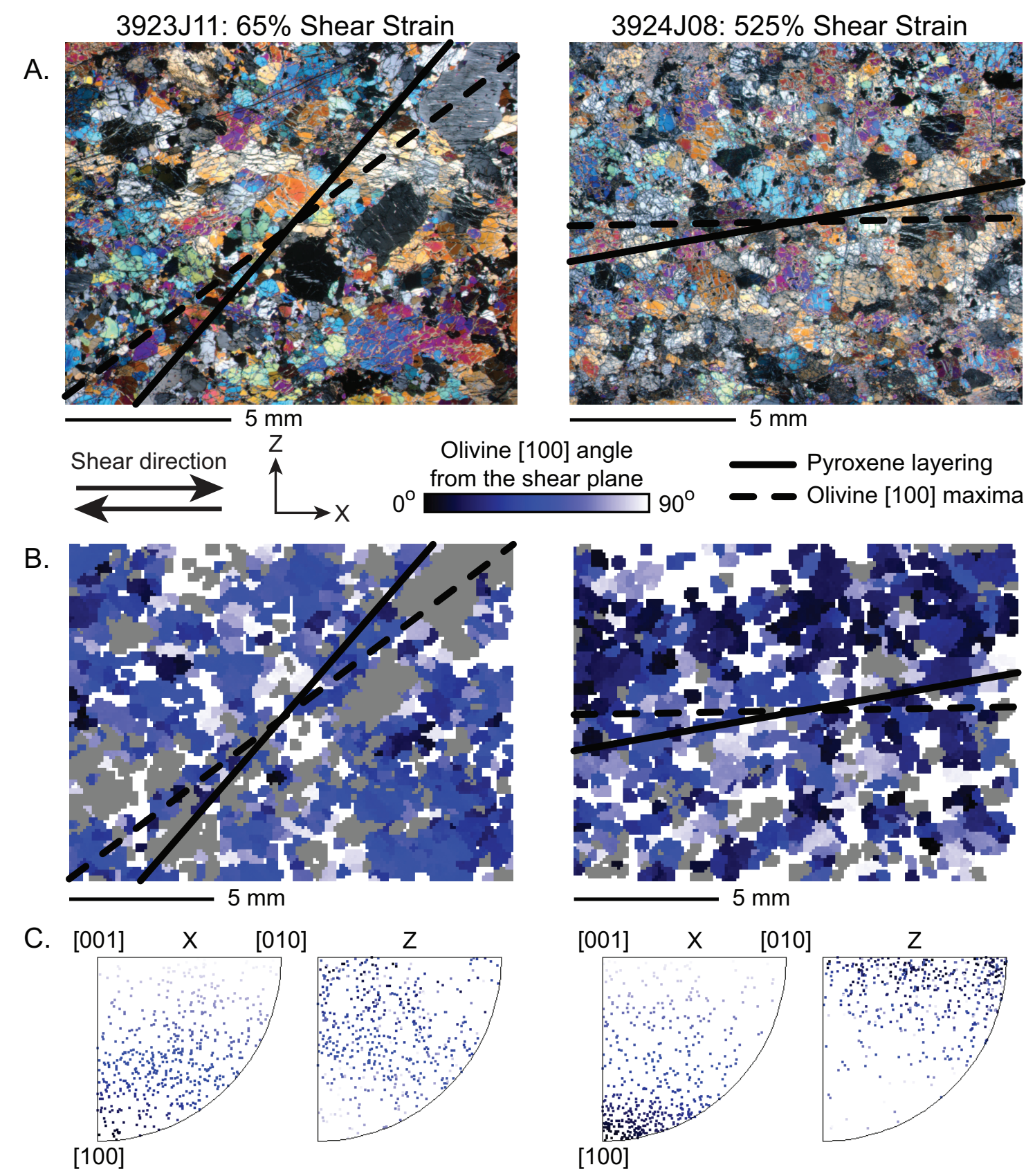

Figure 3: (A) Cross-polarized photomicrographs of two Josephine harzburgites. Solid lines are field measurements of pyroxene layer orientation and dashed lines are orientations of olivine [100] maxima determined by EBSD. Note that the high strain sample is more altered, especially among pyroxenes, and has more cracks and holes. (B) EBSD maps of the same areas. Pyroxenes and spinels are grey and areas with no data are white. Olivine is shaded as a function of the [100] axis angle from the shear plane. (C) Inverse pole figures (upper hemisphere) for olivine, for orientations parallel $(\mathrm{X})$ and perpendicular $(\mathrm{Z})$ to the shear plane. At low strain, grains are oriented with their axes at an angle to both the $\mathrm{X}$ and $\mathrm{Z}$ directions. At high strain, the majority of grains are oriented with [100] parallel to $\mathrm{X}$ and either [010] or [001] parallel to Z. 


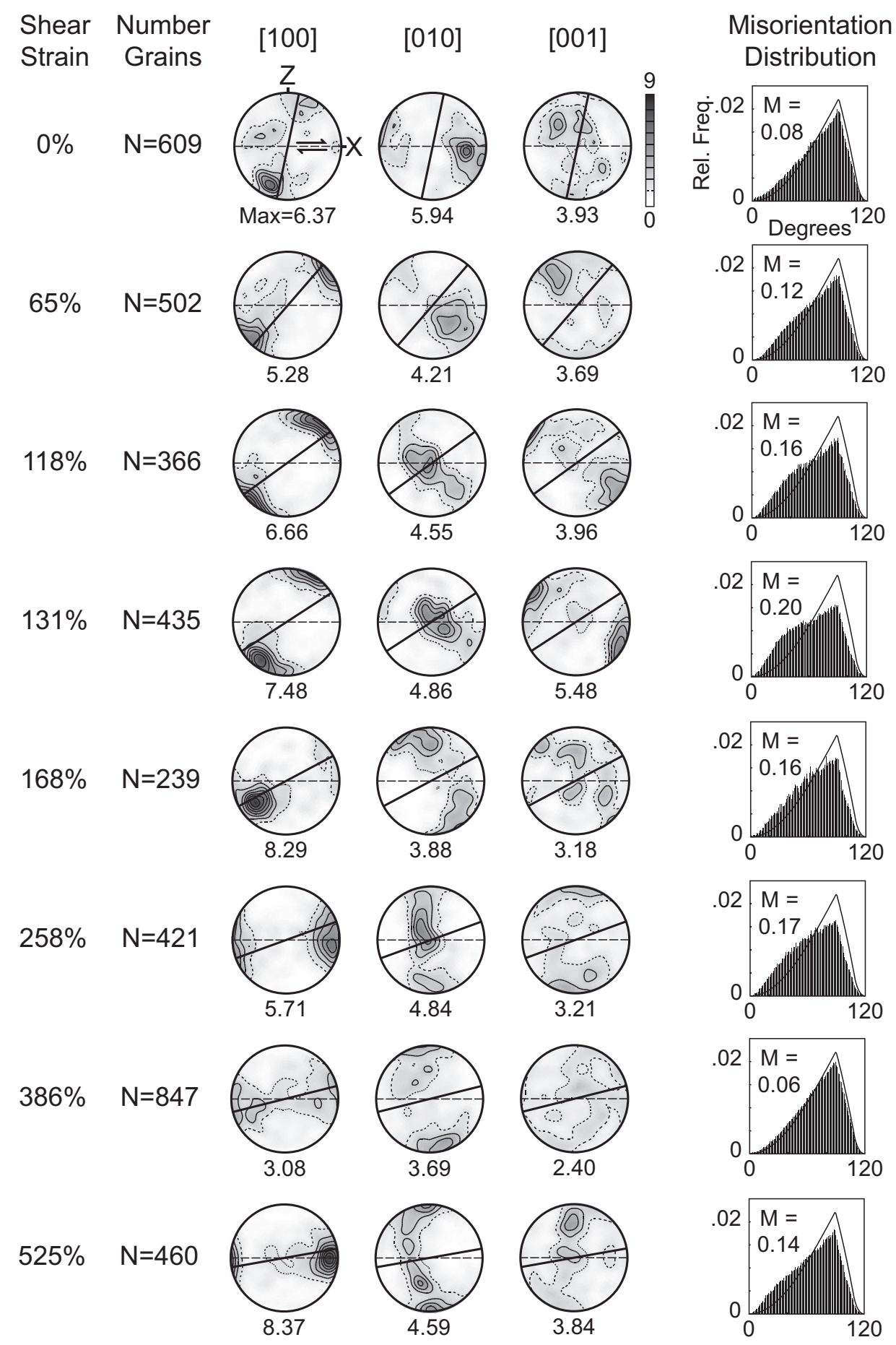

Figure 4: Olivine pole figures (lower hemisphere) for harzburgites. Dashed line is the shear plane and solid line is the pyroxene layering. Contours are multiples of a uniform distribution (MUD), with a dashed line at 1 MUD. Maximum MUD values are identified below each individual pole figure. Misorientation distributions are for uncorrelated angles, with M-index values indicated. The solid line is the theoretical orthorhombic random distribution (Grimmer, 1979). 


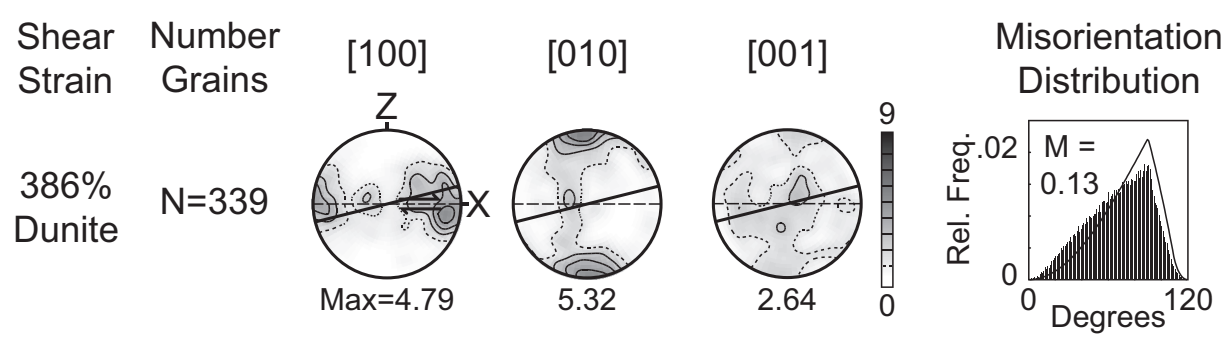

Figure 5: Olivine pole figure and misorientation distribution for a high strain dunite sample. As in Fig. 4, the pole figure is oriented with the shear plane (dashed line) parallel to $\mathrm{X}$, the pyroxene layering indicated by a solid line, and contouring from 0 to 9 MUD. In contrast to the high strain harzburgites, the dunite has more pronounced [100] and [010] maxima. 
3923J01: 0\% Shear Strain
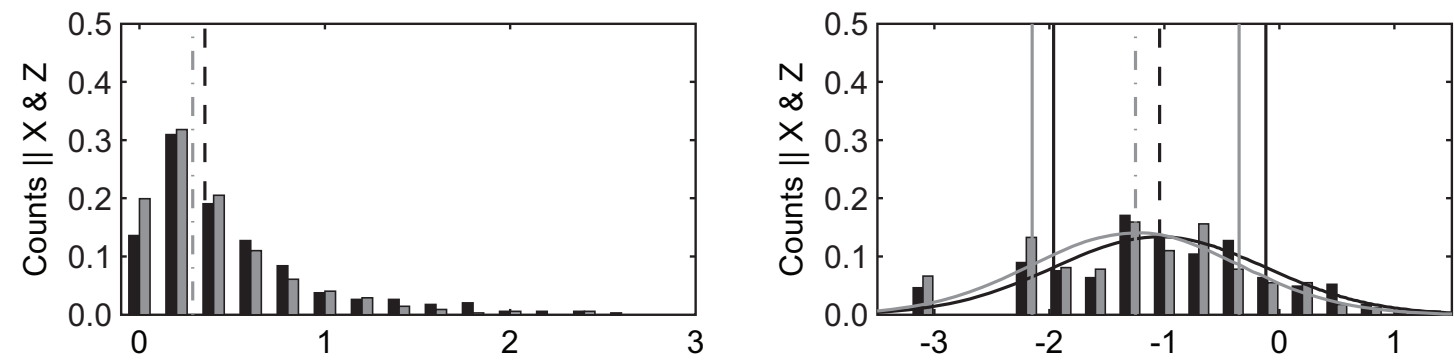

3923J11: $65 \%$ Shear Strain
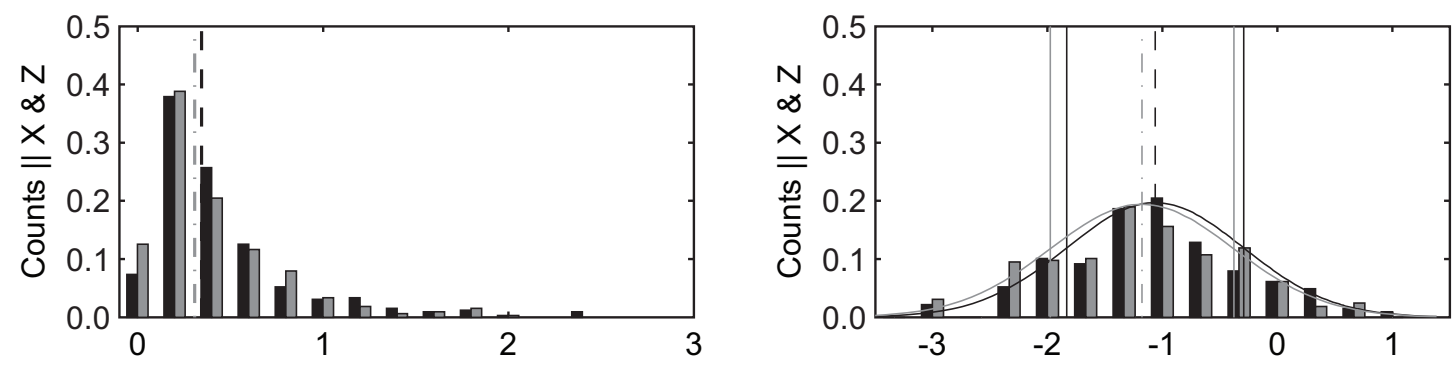

3924J08: $525 \%$ Shear Strain
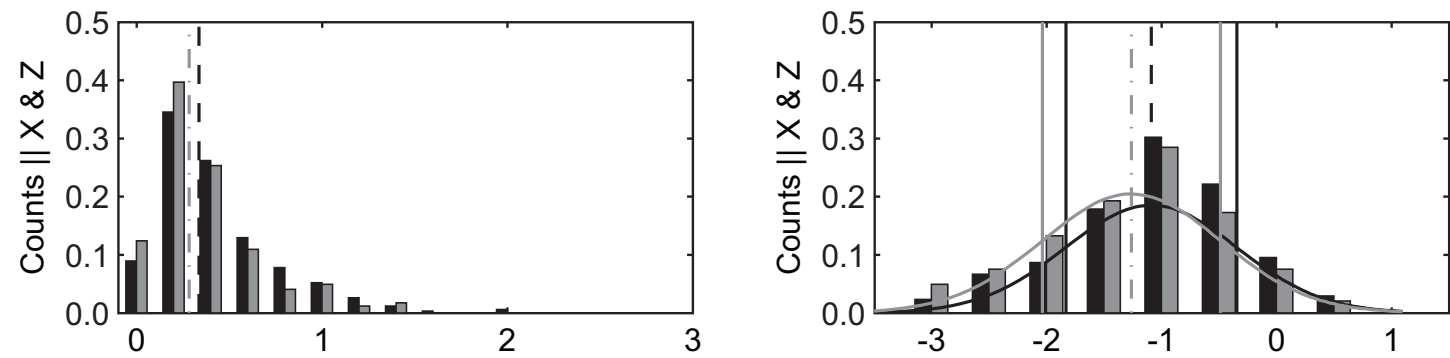

3924J09b: 386\% Shear Strain, Dunite
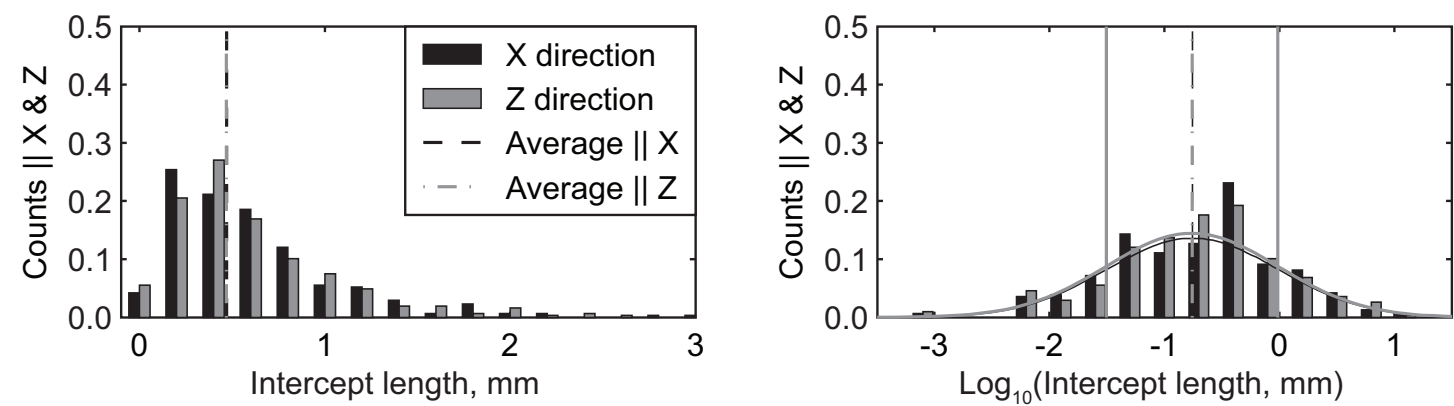

Figure 6: Histograms and log-normal histograms of grain intercept length, parallel (X, black) and perpendicular ( $Z$, grey) to the shear direction. Dashed lines are the geometric mean intercept length in the $\mathrm{X}$ (dashed) and $\mathrm{Z}$ (dot-dashed) directions and solid lines indicate the $1 \sigma$ log-normal standard deviation about the mean. The grain size distributions are approximately log-normal, as demonstrated by the solid curves, which are calculated from the mean and standard deviations of the distributions. 


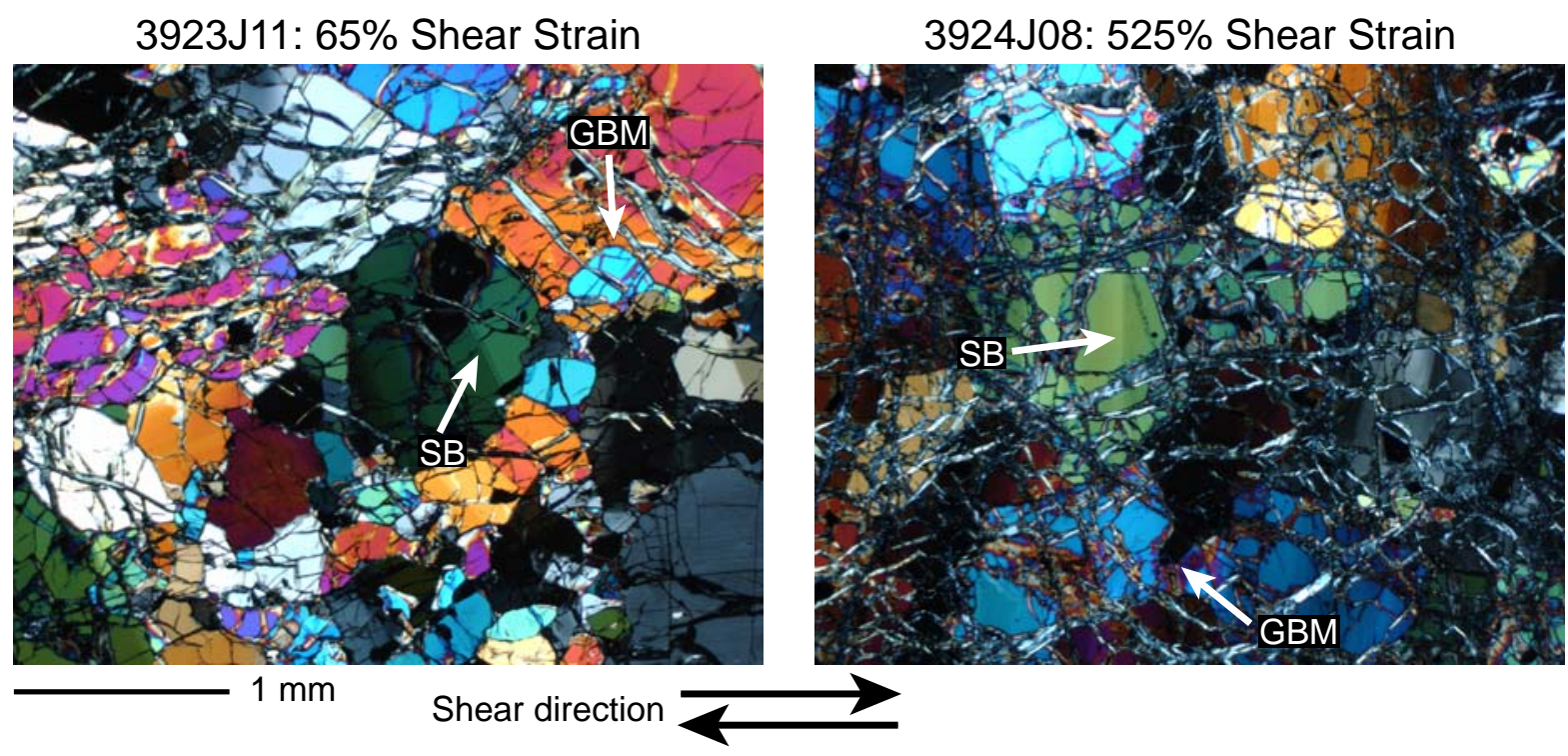

Figure 7: Enlarged photomicrographs of the two harzburgites shown in Fig. 3, showing microstructural details of the samples. Subgrain boundaries (SB) and grain boundary migration (GBM) features are indicated by white arrows. Photomicrographs are taken under crossed-polarized light and in the same orientation as Fig. 3. 


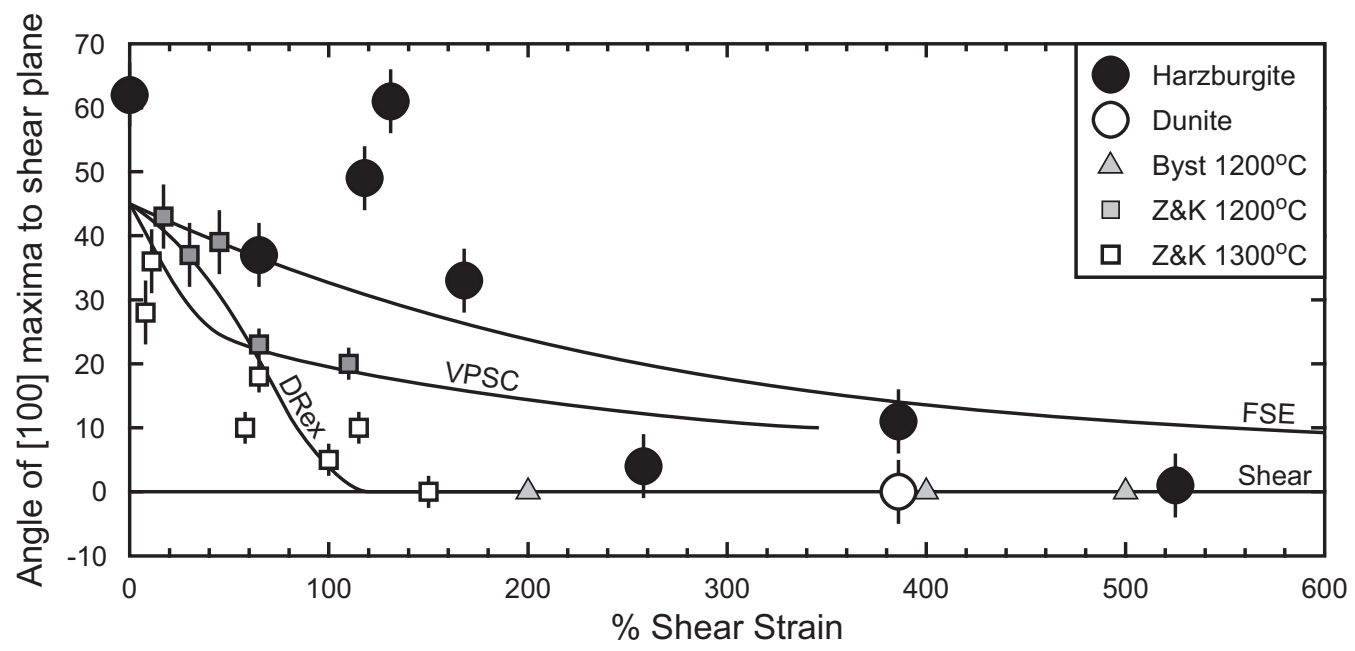

Figure 8: Angle of the olivine [100] maximum to the shear plane as a function of shear strain in the Josephine peridotites, experiments and models. The Josephine harzburgites are shown as filled circles and the dunite as an open circle. The models and experiments initially have random fabrics, represented by an average angle of $45^{\circ}$ to the shear direction. The experimental data are from Bystricky et al. (2000) and Zhang and Karato (1995). The simplest models are FSE, which follows the finite strain ellipsoid and Shear, which follows the shear direction. VPSC is the best fit $(\alpha=100)$ of the viscoplastic self-consistent model (Tommasi et al., 2000) to the experiments. DRex is the best fit $\left(M^{*}=200\right)$ of the dynamic recrystallization model (Kaminski and Ribe, 2001) to the experiments. Similar results to DRex were reported by Wenk and Tomé (1999) using a VPSC model that includes recrystallization. 

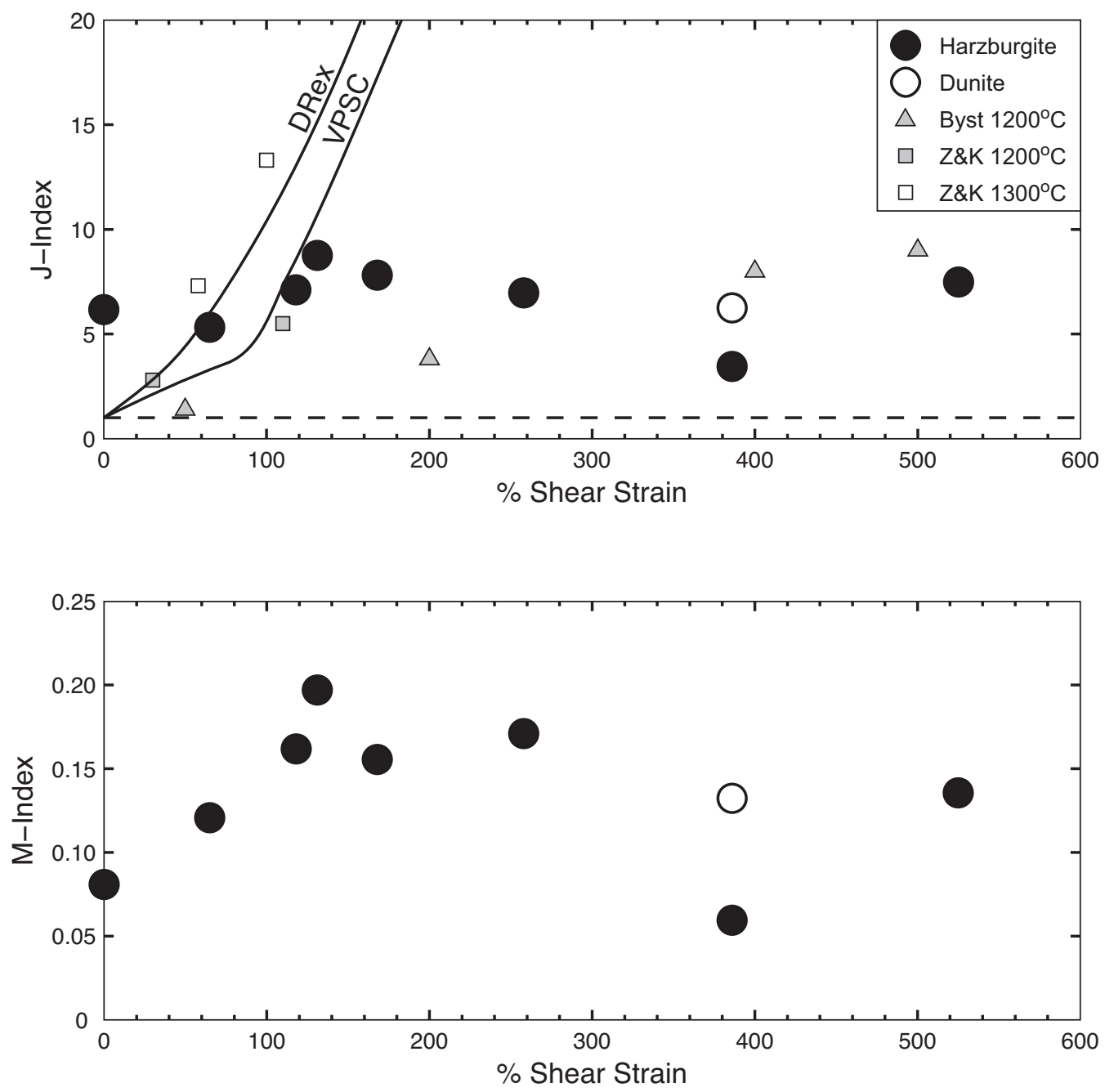

Figure 9: (A) Variation in the J-index as a function of shear strain. Dashed line indicates the theoretical lower limit (i.e. a random fabric) for the J-index. The results for the Josephine harzburgites are shown as filled circles and the dunite as an open circle. Also shown are the Bystricky et al. (2000) high strain experiments, the Zhang and Karato (1995) experiments (from the J-index calculation by Tommasi et al., 2000), the VPSC model ( $\alpha=100$; Tommasi et al., 2000) and the DRex model ( $M^{*}=200$; Kaminski and Ribe, 2001). (B) Variation in the M-index as a function of shear strain in the Josephine samples. The M-index varies between 0 for a random fabric and 1 for a single crystal fabric (Skemer et al., 2005). 


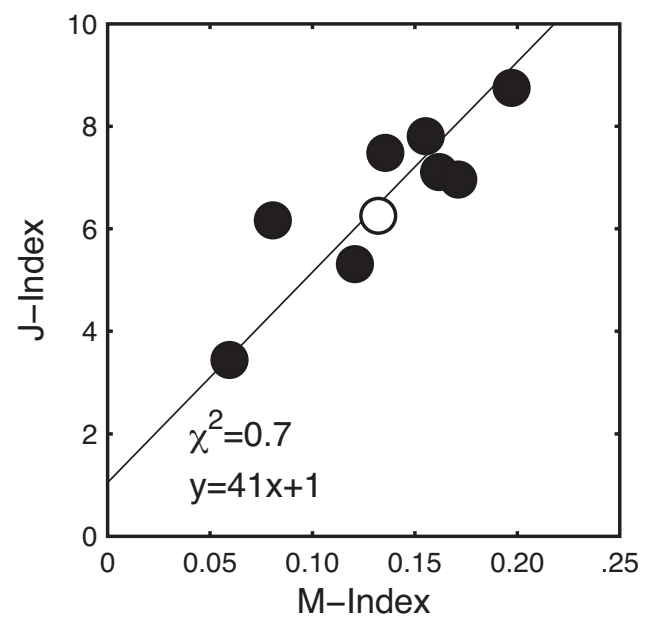

Figure 10: Variation of the J-index versus the M-index for the Josephine samples. Filled circles are harzburgites and the open circle is the dunite. The line is a minimum least squares regression through the dataset.

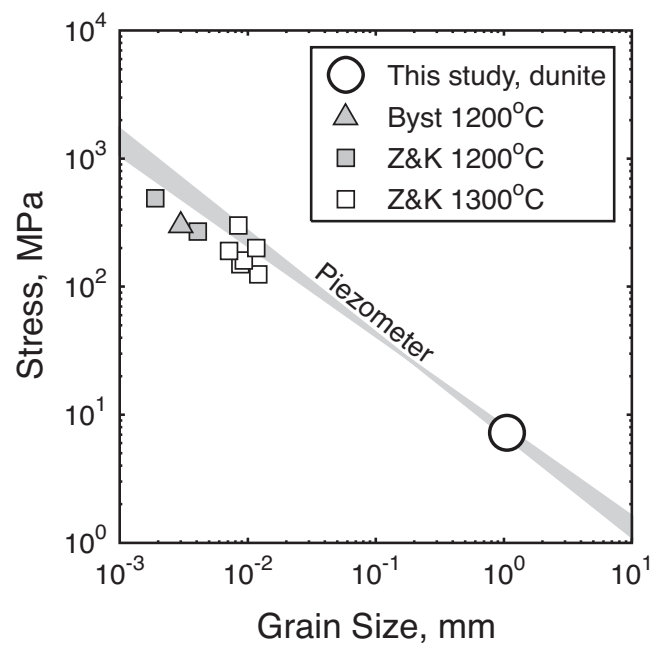

Figure 11: The olivine piezometer - the variation of stress with grain size - as determined from experimental data for dunites (Karato et al., 1980; Van der Wal et al., 1993). The Josephine shear zone deformed at $\sim 7 \mathrm{MPa}$, based on the dunite grain size (open circle) and the piezometer. Also shown are the Zhang and Karato experiments, from the analysis by Zhang et al. (2000), and the Bystricky et al. (2000) experiments. The Zhang and Karato dataset has been adjusted to a geometric correction factor of 1.75 (Van der Wal, 1993), for consistency with our results and the piezometer. 
Table 1: Sample locations, strikes and dips, and the results of strain and fabric analyses.

\begin{tabular}{|c|c|c|c|c|c|c|c|c|c|}
\hline \multirow[b]{2}{*}{ Sample } & \multirow[b]{2}{*}{ Lithology } & \multicolumn{2}{|c|}{ Location (m) } & \multirow{2}{*}{$\begin{array}{c}\text { Field } \\
\text { Strike/Dip }\end{array}$} & \multirow{2}{*}{$\begin{array}{l}\text { Rot\&Proj }^{a} \\
\text { Strike/Dip }\end{array}$} & \multirow{2}{*}{$\begin{array}{l}\text { Shear } \\
\text { Strain }\end{array}$} & \multicolumn{3}{|c|}{ Angle $^{b}$} \\
\hline & & X & $\mathrm{Z}$ & & & & $\alpha^{\prime}$ & $\theta^{\prime}$ & [100] \\
\hline 3923J01 & Harzburgite & 6.2 & 22.2 & $245 / 10$ & $192 / 90$ & $0 \%$ & $78^{\circ}$ & $\mathrm{n} / \mathrm{a}$ & $62^{\circ}$ \\
\hline 3923J02 & Dunite & 4.9 & 23.4 & & & & & & \\
\hline 3923J03 & Harzburgite & 8.9 & 18.9 & $210 / 30$ & $216 / 90$ & $51 \%$ & $54^{\circ}$ & $38^{\circ}$ & \\
\hline 3923J04 & Dunite & 8.9 & 17.4 & & & & & & \\
\hline 3923J05 & Dunite & 8.9 & 21.0 & & & & & & \\
\hline 3923J06 & Harzburgite & 4.1 & 22.2 & & & & & & \\
\hline 3923J07 & Dunite & 4.1 & 23.4 & $200 / 25$ & 208/90 & $32 \%$ & $62^{\circ}$ & $40^{\circ}$ & \\
\hline 3923J08 & Dunite & 8.3 & 13.5 & & & & & & \\
\hline 3923J09 & Harzburgite & 8.3 & 13.5 & $210 / 40$ & $226 / 90$ & $81 \%$ & $44^{\circ}$ & $34^{\circ}$ & \\
\hline $3923 \mathrm{~J} 10$ & Harzburgite & 4.5 & 15.5 & & & & & & \\
\hline 3923J11 & Harzburgite & 4.5 & 15.5 & $210 / 35$ & $221 / 90$ & $65 \%$ & $49^{\circ}$ & $36^{\circ}$ & $37^{\circ}$ \\
\hline $3923 \mathrm{~J} 12$ & Dunite & 6.8 & 12.7 & & & & & & \\
\hline $3923 \mathrm{~J} 13$ & Harzburgite & 6.8 & 12.7 & $215 / 47$ & $234 / 90$ & $118 \%$ & $36^{\circ}$ & $30^{\circ}$ & $49^{\circ}$ \\
\hline 3923J14 & Harzburgite & 0.0 & 7.7 & $210 / 52$ & $237 / 90$ & $131 \%$ & $33^{\circ}$ & $28^{\circ}$ & $61^{\circ}$ \\
\hline 3924J01 & Harzburgite & -3.6 & 5.6 & & & & & & \\
\hline 3924J02 & Dunite & -4.4 & 10.7 & & & & & & \\
\hline $3924 J 03 a$ & Harzburgite & -1.1 & 3.6 & $215 / 70$ & $254 / 90$ & $337 \%$ & $16^{\circ}$ & $15^{\circ}$ & \\
\hline $3924 J 03 b$ & Dunite & -1.1 & 3.6 & $215 / 70$ & $254 / 90$ & $337 \%$ & $16^{\circ}$ & $15^{\circ}$ & \\
\hline 3924J04 & Dunite & -1.0 & 6.1 & & & & & & \\
\hline 3924J05 & Dunite & -4.4 & 1.5 & & & & & & \\
\hline 3924J06 & Harzburgite & -4.4 & 1.5 & $215 / 65$ & $250 / 90$ & $258 \%$ & $20^{\circ}$ & $19^{\circ}$ & $4^{\circ}$ \\
\hline 3924J07 & Dunite & -5.0 & 0.0 & & & & & & \\
\hline 3924J08 & Harzburgite & -5.0 & 0.0 & $217 / 65$ & $260 / 90$ & $525 \%$ & $10^{\circ}$ & $10^{\circ}$ & $1^{\circ}$ \\
\hline 3924J09a & Harzburgite & -3.7 & -0.5 & $218 / 65$ & $256 / 90$ & $386 \%$ & $14^{\circ}$ & $14^{\circ}$ & $11^{\circ}$ \\
\hline $3924 J 09 b$ & Dunite & -3.7 & -0.5 & $218 / 65$ & $256 / 90$ & $386 \%$ & $14^{\circ}$ & $14^{\circ}$ & $0^{\circ}$ \\
\hline 3924J10 & Harzburgite & -1.5 & -2.4 & $214 / 56$ & $242 / 90$ & $168 \%$ & $28^{\circ}$ & $25^{\circ}$ & $33^{\circ}$ \\
\hline 3924J11 & Dunite & -1.5 & -2.0 & & & & & & \\
\hline $3924 \mathrm{~J} 12$ & Dunite & -0.8 & -2.9 & $215 / 55$ & $242 / 90$ & $165 \%$ & $28^{\circ}$ & $25^{\circ}$ & \\
\hline $3924 \mathrm{~J} 13$ & Harzburgite & 0.8 & -6.2 & $215 / 43$ & $231 / 90$ & $100 \%$ & $39^{\circ}$ & $32^{\circ}$ & \\
\hline 3924J14 & Dunite & -0.6 & -6.9 & & & & & & \\
\hline 3924J15 & Harzburgite & -1.9 & -9.4 & $213 / 24$ & $210 / 90$ & $36 \%$ & $60^{\circ}$ & $40^{\circ}$ & \\
\hline 3924J16 & Harzburgite & -3.3 & -12.5 & $214 / 18$ & 203/90 & $21 \%$ & $67^{\circ}$ & $42^{\circ}$ & \\
\hline 3924J17 & Dunite & -5.0 & -13.2 & & & & & & \\
\hline $3924 J 18$ & Harzburgite & -4.4 & -14.2 & $228 / 18$ & $204 / 90$ & $23 \%$ & $66^{\circ}$ & $42^{\circ}$ & \\
\hline 3924J19 & Harzburgite & -0.8 & -22.9 & $230 / 10$ & $193 / 90$ & $2 \%$ & $77^{\circ}$ & $45^{\circ}$ & \\
\hline
\end{tabular}

${ }^{a}$ Data have been rotated and projected onto the plane 305/50.

${ }^{b}$ Counterclockwise angle from shear plane to pyroxene foliation $\left(\alpha^{\prime}\right)$, finite strain ellipse $\left(\theta^{\prime}\right)$, and olivine [100] maximum. 
Table 2: Results of olivine grain size analyses.

\begin{tabular}{llcccccccccc}
\hline & & \multicolumn{4}{c}{ Number } & \multicolumn{4}{c}{ Arithmetic Mean $^{a}$} & \multicolumn{4}{c}{ Geometric Mean $^{b}$} \\
Sample & Lith & Strain & of Grains & X & Z & X\&Z & X/Z & X & Z & X\&Z & X/Z \\
\hline 3923J01 & Harz & $0 \%$ & 346 & 0.53 & 0.42 & 0.47 & 1.27 & 0.35 & 0.29 & 0.32 & 1.23 \\
3923J11 & Harz & $65 \%$ & 327 & 0.46 & 0.42 & 0.44 & 1.11 & 0.35 & 0.31 & 0.33 & 1.12 \\
3924J08 & Harz & $525 \%$ & 348 & 0.44 & 0.37 & 0.40 & 1.17 & 0.34 & 0.28 & 0.31 & 1.19 \\
3924J09b & Dun & $386 \%$ & 307 & 0.61 & 0.60 & 0.61 & 1.01 & 0.47 & 0.47 & 0.47 & 1.00 \\
\hline
\end{tabular}

${ }^{a}$ Average line intercept lengths, not adjusted for grain geometry. For comparison to the Van der Wal et al. (1993) olivine piezometer, apply a geometric correction factor of 1.75. For comparison to olivine flow laws (Hirth and Kohlstedt, 2003), apply a correction factor of 1.5.

${ }^{b}$ Geometric means (also not adjusted for grain geometry) calculated parallel to $\mathrm{X}$, to $\mathrm{Z}$, for $\mathrm{X}$ and $\mathrm{Z}$ combined and for the $\mathrm{X} / \mathrm{Z}$ aspect ratio.

Table 3: Details of the fabric analyses for the Josephine samples.

\begin{tabular}{lccccccc}
\hline & & \multicolumn{2}{c}{ Shear } & \multicolumn{3}{c}{ Axis Maximum $^{a}$} & \multicolumn{2}{c}{ Fabric Strength } \\
Sample & Lith & Strain & {$[100]$} & {$[010]$} & {$[001]$} & J-Index & M-Index \\
\hline 3923J01 & Harz & $0 \%$ & $20 / 208$ & $23 / 100$ & $51 / 337$ & 6.2 & 0.08 \\
3923J11 & Harz & $65 \%$ & $11 / 233$ & $45 / 129$ & $28 / 339$ & 5.3 & 0.12 \\
3923J13 & Harz & $118 \%$ & $00 / 221$ & $81 / 214$ & $16 / 123$ & 7.1 & 0.16 \\
3923J14 & Harz & $131 \%$ & $11 / 209$ & $74 / 091$ & $06 / 298$ & 8.8 & 0.20 \\
3924J06 & Harz & $258 \%$ & $11 / 086$ & $67 / 333$ & $10 / 180$ & 7.0 & 0.17 \\
3924J08 & Harz & $525 \%$ & $22 / 089$ & $06 / 171$ & $39 / 009$ & 7.5 & 0.14 \\
3924J09a & Harz & $386 \%$ & $02 / 259$ & $04 / 345$ & $49 / 065$ & 3.4 & 0.06 \\
3924J09b & Dun & $386 \%$ & $18 / 090$ & $02 / 359$ & $73 / 215$ & 6.3 & 0.13 \\
3924J10 & Harz & $168 \%$ & $31 / 237$ & $10 / 339$ & $69 / 041$ & 7.8 & 0.16 \\
\hline
\end{tabular}

${ }^{a}$ Dip and dip direction of the olivine axis maximum, based on eigenvector analysis provided by the Mainprice program PFch5.app. The dip angle is for a lower hemisphere projection and the dip direction is a clockwise rotation from $\mathrm{Z}$. The olivine axis maximum is assumed to be accurately represented by the first eigenvector of the orientation tensor, which represents the mean direction of a crystal axis (Woodcock, 1977). 